\title{
A SOLIDÃO NO PODER NAS ORGANIZAÇÕES
}

\author{
Patrícia Amélia Tomei* \\ Graziela Fortunato**
}

RESUIMO

$\mathbb{E}$

ste artigo analisa o sentimento de solidão nas organizações. Consideramos diferentes solidão e solitude. A solidão no poder pode ser relacionada com a solidão que, em inglês, é designada pela palavra "loneliness": tem uma conotação negativa e é marcada pelo sentido de isolamento. Já a solitude pode ser relacionada à solidão do poder, em que temos a escolha de estar só sem que, necessariamente, nos sintamos sozinhos. Foram realizadas entrevistas com oito líderes de grandes organizações brasileiras, avaliadas por meio de Análise de Conteúdo. Os resultados indicam que as alternativas criativas e algumas vezes inovadoras têm maior probabilidade de florescer na solidão do poder, pois ativam e reforçam a prática da responsabilidade. A solidão no poder é inerente ao papel da liderança e à tomada de decisão. Para que tenhamos uma organização de aprendizagem, é preciso incentivar a aprendizagem individual e capacitar a elite gerencial para assumir riscos e possíveis erros advindos de uma prática solo.

\section{ABSTRACT}

his article analyses the feeling of loneliness at the top positions in organizations. We make a distinction between solitude and loneliness. The first is a decision of being alone and the feeling is not negative. The former is a negative feeling when people feel isolated. We interviewed top executives in eight important Brazilian organizations through the methodology of Content Analysis. The results indicate that the creative and sometimes innovative ideas flourish best in solitude since it activates the sense of responsibility. Solitude at the top is associated to leadership and decision making. Learning organizations should enhance individual learning and qualify their top management to deal with the responsibility of being a solo practioner.

\footnotetext{
* Profa da Pontifícia Universidade Católica do Rio de Janeiro/PUC-Rio

**Doutoranda PUC/Rio
} 
fenômeno da solidão é universal no tempo e no espaço, atingindo todos os povos. Torna-se cada vez mais corrente a idéia de que a solidão é uma das características que mais definem o homem moderno.

Estudar esse sentimento é um caminho importante para melhor compreendermos o indivíduo. No entanto, a análise do significado da solidão nas organizações modernas é um tema pouco discutido na teoria gerencial. Nos estudos do comportamento humano nas organizações, encontramos uma vasta literatura sobre necessidades, desejos, expectativas, frustrações, fatores de motivação, satisfação, características de personalidade, valores, crenças e comportamentos. Poucos são os trabalhos que pincelam sentimentos, expressões e impulsos dos indivíduos e os relacionam ao contexto organizacional.

Neste artigo, investigaremos a relação entre o sentimento de solidão, isto é, o sentimento de estar só, independentemente de circunstâncias externas, e o desempenho na dinâmica organizacional.

Consideraremos dois tipos de solidão: positiva e negativa. A solidão positiva é a necessidade que os indivíduos sentem de se afastar dos outros em determinados momentos. Nesses momentos, mesmo que seja doloroso, o isolamento é construtivo e necessário para refazer energias e para desabrochar o processo criativo e inovativo. A solidão negativa é o isolamento do indivíduo ao sentir-se rejeitado pela sociedade e/ou pela organização em que trabalha, ou ao se perceber não enquadrado nos padrões estabelecidos pela cultura organizacional. Esse isolamento, quando insuportável, pode levar o indivíduo a atitudes agressivas e, em alguns casos, até à depressão, afetando a motivação e a produtividade no trabalho.

O objetivo final deste artigo é analisar a solidão no poder, subordinada à eficiência organizacional segundo duas grandes famílias de assunto que permeiam os fundamentos do pensamento gerencial: a Tomada de Decisão e o Papel da Liderança.

Assim sendo, este artigo busca responder as seguintes questões:

(1) Como a gestão considera a participação decisória do grupo em questões fundamentais da organização?

(2) De que forma as lideranças organizacionais percebem a solidão? Como algo positivo ou negativo para o desempenho da função?

A sociedade e as organizações, de forma particular, consideram o "estar só" como um sentimento negativo, pois carrega o peso de sentimentos associados ao isolamento, rejeição, individualismo e centralização. Neste artigo, partiremos da premissa de que estar só é necessário para que um líder possa pensar em soluções criativas e inovadoras. A solidão, nesse caso, é positiva. Portanto, a abordagem desse tema se fundamenta em dois pontos:

(1) Decisões estratégicas demandam do decisor um isolamento e um distanciamento emocional para que este ofereça alternativas mais criativas e gestão mais inovadora,

(2) Existe um paradoxo e, também, um desafio entre a necessidade da prática gerencial de estar só e o discurso que permeia toda a teoria organizacional, no qual se incentiva o trabalho em equipe e a gestão participativa.

O artigo está dividido em seis partes, incluindo esta introdução. A seguir, apresenta-se o referencial teórico, conceituando a questão da solidão e a sua relação com a tomada de decisão individual e grupal. Na terceira parte, descrevemos a metodologia adotada. Na quarta, são mostrados os resultados e as análises das entrevistas; e, por fim, conclui-se o artigo. 
Referernciall Teórico

A solidão não é tema atual. A solidão aflige o homem desde sua origem, apesar de não se tratar de assunto inovador. Na idade moderna, a solidão se faz presente na medida em que o homem se confunde na multidão que o cerca e se encontra sozinho no meio de uma massa anônima. Há uma padronização, na qual todos são iguais, mas não se relacionam, e os vínculos de solidariedade estão enfraquecidos. Nos tempos modernos, é a comunidade que dilui o sentimento de solidão e dá às pessoas a sensação de pertencerem a um grupo.

Por sentimento de solidão não se entende, necessariamente, uma situação objetiva de estar privado de companhia. Segundo Klein (1971), solidão é o sentimento de estar só, de sentir-se solitário, mesmo quando entre amigos ou recebendo amor, ou seja, independe de circunstâncias externas. A solidão também pode ser definida como uma condição de estado emocional fragilizado, que é natural do ser humano quando este se sente estranho ao grupo, não compreendido ou rejeitado. A solidão é gerada, ainda, pela sensação de ausência de companhia em que haja afinidades semelhantes para atividades desejadas, particularmente as que necessitam de um senso de integração social. De acordo com Klein (1971), quando se experimenta um intenso sentimento de solidão, há uma grande necessidade de se buscar objetos externos, uma vez que a solidão se afugenta, parcialmente, pelos relacionamentos externos. As influências externas, especialmente a atitude de pessoas significativas para o indivíduo, podem, de outras maneiras, minorar a solidão. A valorização dos outros e do êxito - originariamente a necessidade infantil de ser valorizado pela mãe - pode ser utilizada como defesa contra a solidão. Tal método se revela, porém, muito ineficaz quando utilizado em excesso, uma vez que a confiança em si não se estabelece suficientemente.

Sartre (1978) considera, em sua obra, que a solidão humana radica na impossibilidade de uma efetiva comunicação com o outro. Existem dois momentos de grande significação do contexto em que o autor coloca o encontro com o outro. 0 primeiro refere-se ao momento em que o homem, ao sentir-se olhado ou ao pressentir a presença do outro, perde sua autonomia original: o segredo de seu ser passa a ser a propriedade do outro. "Sou como o outro me vê..." (SARTRE, 1978). Daí a necessidade que todo ser humano sente de relacionar-se com o próximo, pois é no outro que se encontra a chave do seu ser. $\mathrm{O}$ segundo momento acontece quando, transformado em objeto pelo olhar do outro, o ser olhado reage e devolve o olhar que o constrange, transformando-se então em ser "olhante". Neste momento, fica caracterizado o conflito, raiz de todo relacionamento.

Autores como Angerami (1986), May (1987) e Tanner (1979) têm afirmado que em todas as épocas, a solidão foi temida e as pessoas procuraram fugir dela. O que ocorre é que, em nossa época, é que o medo da solidão é muito mais intenso, e as defesas contra ela, tais como diversões, atividades sociais e amizades, são amplas e compulsivas.

Segundo Weiss (1974), a solidão não é causada por estar sozinho, mas por estar sem uma forma específica de relacionamento ou conjunto de relacionamentos. Quando o tipo de relação da qual se sente falta aflora, a solidão desaparecerá abruptamente, como se nunca tivesse existido. Não há recuperação gradual; não é um estado que se possa "superar aos poucos". O autor nos fala da solidão como algo desejável, no sentido de que a separação dos outros oferece um "retorno a si mesmo". Esse é o tipo de situação em que a pessoa não está apenas sozinha, mas também é capaz de usar sua solidão para reconhecer com clareza tanto a sua separação de todo o resto, como sua conexão fundamental com todo o resto. A pessoa é, então, capaz de reconhecer seu eu mais profundo e, assim, começar a ser esse ser verdadeiro. 
Weiss (1974) diferencia a "solidão do isolamento emocional" da "solidão do isolamento social". A primeira seria aquela provocada pela falta de um relacionamento emocional íntimo, e só poderá ser "curada" mediante a integração de um outro relacionamento da mesma espécie ou pela reintegração de um relacionamento que foi perdido. A última, por sua vez, está associada com a ausência de uma rede de relacionamentos sociais, e só poderá ser revertida mediante um engajamento em tal espécie de rede.

A palavra solidão, na maioria das vezes, possui conotação negativa e é, geralmente, associada com falta, ausência, perda e abandono. A solidão, no entanto, pode não ser tão ameaçadora e penosa para aqueles que possuem a concepção dos valores positivos do isolamento. Existe, na solidão, uma possibilidade para reflexão e criatividade, que é importante numa sociedade massificada, na qual o indivíduo é um ser sem identidade.

Evans (apud SULLIVAN, 1996) nos fala da experiência da solidão associada a pré-adolescentes. Segundo o autor, a solidão, embora difícil de ser descrita, é a motivação fundamental ao desenvolvimento interpessoal na medida que ela é mais poderosa que a ansiedade. A pessoa acaba por buscar companhia mesmo que esta venha a trazer mais ansiedade. Segundo Sullivan (1996): "O fato de a solidão levar a um estado de severa ansiedade automaticamente significa que a solidão por si só é mais terrível que a ansiedade."

Gustafsson (1994), poeta, filósofo e romancista sueco, afirma que todas as pessoas são solitárias e que há vários tipos de solidão. Há pessoas socialmente isoladas e outras não, com uma espécie de solidão da própria existência. Ele acrescenta, ainda, que na vida há um isolamento fundamental em cada um de nós. Nunca podemos nos transformar em outra pessoa, não podemos sentir a dor do outro, fugir do nosso próprio corpo e nos instalar no outro. Estamos sozinhos com a nossa solidão.

Katz (1996) nos fala que é preciso aprender a ser só e parte da convicção de que nem sempre isolamento rima com sofrimento, ou seja, há uma solidão positiva. O autor prega o direito de não se comunicar, de não externar sentimentos e opiniões ou compartilhar momentos quando o mundo tagarela dos meios de comunicação exige justamente o contrário. Este resgata a genealogia histórica da solidão positiva em Santo Agostinho (1984), Kant (1787), Santa Teresa D'Avila (apud ROSSI, 1988), Spinoza (apud DELEUZE, 1981) e Foucault (1972). Além disso, aborda que a passagem do pensamento para a vida não deve ser simplista e imediata como as pregações da maioria dos livros de auto-ajuda. Essa passagem deve permitir que a convivência com a solidão ensine aos indivíduos não simplesmente a conviverem com a ausência de algo ou de alguém, mas, ao contrário, fazerem dessa falta um fator de fortalecimento. Para o autor, boas companhias podem apenas aliviar o sentimento de solidão; para uma realização pessoal, é necessário um profundo autoconhecimento que só pode ser encontrado no íntimo de cada um.

Segundo Paz (1984), a solidão pode ser positiva na medida em que somente na solidão é possível uma ruptura com um mundo caduco e a criação de um outro novo. A solidão é a profundeza última da condição humana. O homem é o único ser que se sente só e o único que está a busca de outro. Sua natureza consiste num aspirar a se realizar em outro. O homem é nostalgia e busca de comunhão. Por isso, cada vez que se sente a si mesmo, sente-se como carência do outro, como solidão.

Todos os nossos esforços tendem a abolir a solidão. Assim, sentir-se só possui um duplo significado: por um lado, consiste em ter consciência de si; por outro, num desejo de sair de si. A solidão, que é a própria condição de nossa vida, surge para nós como uma prova e uma purgação, ao fim da qual a angústia e a instabilidade desaparecerão. A plenitude, a reunião, que é repouso e felicidade, e a concordância com o mundo nos separam no fim do labirinto da solidão.

Schlanger (1990) nos coloca, de maneira interessante, a metáfora do "pensador de fundo" em analogia ao "corredor de fundo". Segundo ele o "pensador de 
fundo" aborda o pensar pela profundidade e não pela extensão. Para ele, a solidão é um elemento inerente ao trabalho criador. A corrida de fundo é a postura existencial que reflete e amplifica a atividade do pensador de fundo. No estado de espírito do corredor de fundo, há a obstinação, a perseverança, a repetição rítmica - tudo que constitui o arcabouço existencial da atividade do pensador de fundo. A corrida de fundo, como postura existencial, corresponde ao pensamento de fundo como postura reflexiva entre: pensador de fundo em oposição ao pensador de superfície; pensador solitário em oposição ao pensador de grupo; pensador que fala consigo mesmo em oposição ao pensador que se comunica constantemente; pensador do paradigma em oposição ao pensador no paradigma. E, ainda, o autor traça idéias sobre um fundo real, tal como o pintor traça suas linhas sobre a tela branca, como o músico elabora sua trama de sons sobre o fundo de silêncio. Portanto, há a dimensão poética que faz do pensador um criador, um artesão, um artista.

A Tabela 1, a seguir, apresenta um resumo dos conceitos de solidão, segundo os diferentes autores.

Tabela 1 - Resumo dos Conceitos de Solidão

\begin{tabular}{|c|c|}
\hline AUTOR & CONCEITO \\
\hline SARTRE (1978) & $\begin{array}{l}\text { A solidão humana radica na impossibilidade de uma efetiva } \\
\text { comunicação com o outro. }\end{array}$ \\
\hline EVANS (1996) & $\begin{array}{l}\text { A solidão é motivação fundamental ao desenvolvimento } \\
\text { interpessoal, na medida em que ela é mais poderosa que a } \\
\text { ansiedade. }\end{array}$ \\
\hline KLEI N (1971) & $\begin{array}{l}\text { A solidão é o sentimento de estar só, independentemente de } \\
\text { circunstâncias externas. }\end{array}$ \\
\hline WEISS (1974) & $\begin{array}{l}\text { A solidão não é causada por estar sozinho, mas por estar sem uma } \\
\text { forma específica de relacionamento ou conjunto de } \\
\text { relacionamentos: "solidão do isolamento emocional" provocada pela } \\
\text { falta de um relacionamento emocional íntimo, ou "solidão do } \\
\text { isolamento social" provocada pela ausência de uma rede de } \\
\text { relacionamentos sociais. }\end{array}$ \\
\hline $\begin{array}{l}\text { GUSTAFSSON } \\
(1994)\end{array}$ & $\begin{array}{l}\text { Todas as pessoas são solitárias. Há vários tipos de solidão. Na vida } \\
\text { há um isolamento fundamental em cada um de nós. Estamos } \\
\text { sozinhos com a nossa solidão. }\end{array}$ \\
\hline KATZ (1996) & $\begin{array}{l}\text { É preciso aprender a ser só. Nem sempre isolamento rima com } \\
\text { sofrimento. }\end{array}$ \\
\hline PAZ (1984) & $\begin{array}{l}\text { O homem é o único ser que se sente só e o único que é busca de } \\
\text { outro. O homem é nostalgia e busca de comunhão. Por isso, cada } \\
\text { vez que sente a si mesmo, sente-se como carência do outro, como } \\
\text { solidão. Sentir-se só possui um duplo significado: por um lado, } \\
\text { consiste em ter consciência de si; por outro, num desejo de sair de } \\
\text { si. }\end{array}$ \\
\hline $\begin{array}{l}\text { SCHLANGER } \\
(1990)\end{array}$ & $\begin{array}{l}\text { A solidão para "pensador de fundo" é uma postura reflexiva. Ele } \\
\text { aborda o pensar pela profundidade e não pela extensão; é um } \\
\text { elemento inerente ao trabalho criador. } \\
\text { O "corredor de fundo" tem uma postura existencial que reflete e } \\
\text { amplifica a atividade do pensador de fundo, com obstinação, } \\
\text { perseverança e repetição rítmica. Desenvolve postura reflexiva } \\
\text { entre: } \\
\text { Pensador de fundo versus pensador de superfície. } \\
\text { Pensador solitário versus pensador de grupo. } \\
\text { Pensador que fala consigo mesmo versus pensador que se } \\
\text { comunica constantemente. } \\
\text { Pensador do paradigma versus pensador no paradigma. }\end{array}$ \\
\hline
\end{tabular}

Fonte: elaboração própria 
Solitude não é solidão. Na língua inglesa, há duas palavras distintas para designar percepções diferentes do que, popularmente, na língua portuguesa se reduz à palavra sólida. No inglês, a solidão, enquanto condição de estar isolado, desacompanhado, solitário ou abandonado, tem o nome de loneliness. Já a solidão, enquanto isolamento intencional, com objetivo de reflexão, meditação ou mesmo de relaxamento, leva o nome de aloneness. Bem pouco usual para a maioria dos brasileiros, a palavra solitude, embora também exista no espanhol com o mesmo sentido da nossa solidão ou do loneliness, foi introduzida na língua portuguesa para designar exatamente a solidão do silêncio intencional, com alguma finalidade positiva.

A solidão no poder pode ser relacionada com loneliness, na medida em que tem uma conotação negativa e é marcada pelo sentido de isolamento, pela sensação de que alguma coisa está faltando. Já a solidão do poder pode ser relacionada à solitude: uma reação positiva em que temos o estado de estar só sem necessariamente sentir-se sozinho. Conforme colocação de Marano (2003), olhando de fora, a solidão e a solitude parecem semelhantes, na medida em que envolvem um ser solitário. No entanto, tal semelhança é apenas superficial.

Solidão é vazio interior. Solitude é realização interior. Solitude não é, antes de tudo, um lugar, mas um estado da mente e do coração. Há uma solitude do coração que pode ser mantida em todas as ocasiões. As multidões ou a sua ausência têm pouco a ver com este estado atentivo interior. É perfeitamente possível ser um eremita, viver no deserto e, no entanto, nunca experimentar a solitude. Porém, se possuirmos solitude interior, nunca teremos medo de ficar sozinhos, pois sabemos que não estamos sós.

Segundo McPherson et al. (2006), a solidão é um estado emocional no qual o indivíduo experimenta um sentimento de vazio, de ter sido rejeitado, desconectado ou alienado de outras pessoas.

$\mathrm{Na}$ verdade, solidão não significa estar sozinho. A experiência de estar sozinho pode ser positiva, prazerosa e emocionalmente gratificante se está sob o controle do indivíduo. A solitude é o estado de estar sozinho e separado de outras pessoas e, freqüentemente, está relacionado a uma escolha consciente e desejada de estar sozinho. A solitude é algo que cultivamos, é o tempo que pode ser utilizado para reflexão e é a oportunidade de renovação pessoal (CARTER, 2000).

A escola filosófica existencialista considera a solidão como a essência do ser humano: todo o indivíduo vem ao mundo sozinho, navega pela vida como uma pessoa distinta e única, e morre sozinho. Lidar com essa realidade, aceitá-la e aprender a direcionar a sua própria vida com satisfação fazem parte da condição humana.

\section{A solid ão no cotidliano gerenciall}

Nos tempos atuais, faz parte do perfil do líder atuar junto aos seus pares, a fim de que seja formada uma equipe de trabalho e que a gestão seja a mais participativa possível, no estilo "portas abertas". No entanto, na maioria das empresas, ainda pode-se constatar que existe um abismo entre o alto escalão e as pessoas que compõem o restante da pirâmide. Muitas vezes, compartilhar angústias ou dúvidas com os colegas pode acarretar conflitos. Essa elite gerencial, apesar de estar sempre cercada de pessoas, como seus funcionários, clientes e fornecedores, não sente confiança em dividir suas decisões e apreensões, porque essas pessoas que o cercam são vistas como concorrentes (BOYD e GUMPERT, 1992).

A síndrome da solidão do executivo decorre do aumento substancial das responsabilidades. Essas responsabilidades o obrigam a ter de dedicar uma boa parcela de seu tempo em trabalhos que envolvem obtenção de resultados por 
meio do gerenciamento de equipes, ou grupos de equipes, ou ainda unidades de negócio. Existe convergência no discurso empresarial de que as decisões em equipe trazem maior probabilidade de sucesso às organizações, e que a delegação de poder, uma forma de trabalho em equipe, é fundamental para o empowerment e para a aprendizagem individual e organizacional (TOMEI, 1995; 2004).

Conforme observamos nas pesquisas de Mintzberg (1973) e Luthans et al.(1988), referentes aos papéis dos executivos e à alocação de tempo em atividades gerenciais, as habilidades humanas e conceituais que envolvem interconexão (networking), cada vez mais, são demandadas no processo de promoção dentro da organização. Essas habilidades impõem aos tomadores de decisão uma mudança de estilo, uma postura de chefe-líder na qual a gestão de suas próprias emoções e emoções dos outros é fundamental para a obtenção de resultados. Isto requer concentração extra e certo grau de isolamento para reflexão.

É importante que o líder saiba lidar com o isolamento social, com o sentimento de insegurança e o medo de assumir responsabilidades. Foi dessa necessidade em socorrer os executivos e empresários solitários que André Kaufmann e Antônio Clóvis Alves resolveram criar no Brasil, há sete anos, o Renaissance Executive Forums. Eles sentiram na própria pele essa sensação, nem um pouco agradável, quando exerciam o papel de diretores e executivos de empresas. Em entrevista à Revista Vida Executiva, de maio de 2007, Kaufmann declarou: "Sabemos que muitos presidentes, donos de empresas e altos executivos com poder de decisão sentem muita solidão, mas poucos admitem isso. Apenas os que têm maturidade".

Embora, no Brasil, as reuniões de "aconselhamento" entre executivos sejam uma prática ainda pouco conhecida, nos Estados Unidos, milhares de CEOs já bloqueiam as agendas para conseguir superar os dissabores que o poder pode trazer. Associações como a YPO (Young Presidents Organization) e a TEC (The Executive Committee) são exemplos significativos de organizações que inspiraram tais práticas no Brasil. A YPO é uma empresa norte-americana que promove encontros entre grandes executivos e empresários com objetivo de troca de experiências. A TEC, fundada em 1957, com cerca de 14.000 membros em 16 países - hoje, resolveu mudar sua marca para Vistage Internacional - também reúne executivos para troca de experiências. Essas associações têm compromisso com o indivíduo, no sentido de melhorar seu desempenho profissional e sua qualidade de vida. Justificam sua existência em frases como: "Porque liderar é muito solitário", "Melhores líderes, decisões e resultados".

A solichão e o complertannento organizacional

O homem é um animal social cujo comportamento é, em grande parte, determinado pela sua necessidade de estar com outras pessoas e por suas reações a outras pessoas. A importância do contato social já é reconhecida há muito tempo, como se pode ver no uso de prisões solitárias como forma de punição, ou no isolamento voluntário para meditação religiosa.

A literatura e os estudos de campo e de laboratório indicam que o isolamento e o confinamento são estressantes para muitos indivíduos, e que o estresse é, às vezes, tão grave a ponto de causar uma diminuição abrupta no nível de adaptação e desempenho.

A maior parte das situações de isolamento e confinamento envolve um nível de redução de estímulo que a maioria dos indivíduos considera incômodo. Altman e Haythorn $(1965,1967)$ estudaram o desempenho e o comportamento de grupos e concluíram que fatores como estresse, compatibilidade dos membros dos grupos, gênero, idade, cultura, estabilidade emocional, entre outros, podem afetar a coesão dos grupos e seus desempenhos, especialmente em situações de isolamento e confinamento. Assim sendo, para entendermos o papel da solidão no comportamento organizacional e na tomada de decisão em grupo, selecionaremos dois aspectos relevantes do comportamento em grupo: o tamanho do grupo e o pensamento grupal. 


\section{Solidão e Tamanho de Grupo}

Quando analisamos a teoria dos grupos, temos uma nova visão do papel do indivíduo no desempenho. Conforme assinalam Kravitz e Martin (1986), baseados nas pesquisas feitas pelo psicólogo alemão Max Ringelmann na década de 20, o estereótipo comum de que o espírito de equipe estimula o esforço individual e aumenta a produtividade geral do grupo não se fundamenta. Os resultados evidenciaram que o aumento do tamanho do grupo é inversamente proporcional ao desempenho individual. Caso não se efetive um gerenciamento que ofereça os meios de identificação dos esforços individuais, o grupo reage com um comportamento rotulado de "folga social": há a tendência das pessoas se esforçarem menos ao trabalhar em grupo do que se estivessem trabalhando sozinhas (LIDEN et al, 2003; 2004; COMER, 2000).

A principal causa que explica essa folga social está relacionada à motivação, já que as pessoas se sentem desmotivadas quando trabalham em grupo e acreditam que suas contribuições individuais não serão avaliadas. Segundo estudos de Karau e Williams (1993), a folga social é um fenômeno perverso e ocorre, principalmente, quando o indivíduo não se sente valorizado pelo grupo. No entanto, tal folga não ocorre quando os membros do grupo sentem que a tarefa ou o grupo em si é importante.

Segundo Rothwell (2000) e Latane et al. (1979), a resposta para a folga social é a motivação do grupo que pode ser obtido por meio: (a) de esforços para que todos se sintam envolvidos; (b) de conteúdo que identifique a importância de tarefas específicas no grupo e; (c) da oferta aos membros do grupo da escolha de qual tarefa e papel preferem assumir.

Para o gerenciamento dessas questões, Jackson et al. (1985) destacam a importância do papel do líder, que precisa ter o equilíbrio para harmonizar as suas necessidades de participação solo e as necessidades dos membros da sua equipe. Esse equilíbrio somente é viável, por meio do gerenciamento da solidão no poder.

\section{Solidão e Pensamento Grupal}

O pensamento grupal tem recebido atenção especial dos pesquisadores do comportamento organizacional, preocupados com a tomada de decisão em grupo. Tal pensamento, definido como fenômeno, tem o potencial de afetar a capacidade do grupo para avaliar objetivamente as alternativas e chegar a soluções de qualidade. Conforme colocam Choi e Kim (1999) e Esser (2001), esse fenômeno descreve as situações em que pressões para a conformidade impedem que o grupo avalie criticamente propostas incomuns, minoritárias ou impopulares, gerando sintomas como deteriorização da eficiência mental do indivíduo e busca de uma ilusão de unanimidade e moralidade.

Segundo J anis (1972), Baron (2005) e McCauley (1989), nem toda a tomada de decisão é afetada pelo pensamento grupal. Mas para que a organização evite esse fenômeno, entre outras medidas, é fundamental o papel do "avaliador crítico" e do "advogado do diabo". Essa liderança deve estar preparada para reforçar a argumentação e o conflito de idéias, evitando o conformismo, a homogeneidade e a padronização que impõem obstáculos à criatividade e à inovação. Ela precisa respeitar o balanceamento entre a autoridade e a individualidade, o autoritarismo e o individualismo. Tal prática somente é viável num modelo cuja liderança tenha clareza do gerenciamento da solidão no poder (RUSSEL, 1949; GLADWELL, 2005).

\section{Metodologial}

Para a análise da solidão do poder, buscamos compreender as percepções e opiniões dos empresários entrevistados, segundo as duas grandes famílias de 
assunto que permeiam a gestão organizacional: (1) a Tomada de Decisão (TD) e; (2) a Liderança Organizacional (LI).

Para a coleta de dados, nesta pesquisa exploratória, foram feitas entrevistas semi-estruturadas com uma amostra aleatória de oito líderes de primeiro escalão de grandes organizações de diferentes naturezas jurídicas e setor industrial. Cada entrevista teve, aproximadamente, duas horas e meia de duração. Para ter uma noção do tamanho das empresas convidadas a participarem das entrevistas, adotamos como medida de tamanho a receita líquida de 2004, em reais, e o número de funcionários.

Todas essas informações estão apresentadas na Tabela 2, a seguir, e serão úteis como referenciais nos trechos das entrevistas inseridas na análise de resultados.

Tabela 2 - Dados das Empresas

\begin{tabular}{|c|c|c|c|c|}
\hline Empresa & Entrevistado & Setor & Receita (R\$mil) & No. Funcionários \\
\hline Empresa 1 & Entrevistado 1 & esporte & 2,197 & n.d. \\
\hline Empresa 2 & Entrevistado 2 & embalagem & $1,000,000$ & n.d. \\
\hline Empresa 3 & Entrevistado 3 & financeiro & $1,378,506$ & 453 \\
\hline Empresa 4 & Entrevistado 4 & saúde & $2,000,000$ & 9,000 \\
\hline Empresa 5 & Entrevistado 5 & gases industriais & $2,100,000$ & 4,950 \\
\hline Empresa 6 & Entrevistado 6 & cigarro & $3,480,000$ & 5,000 \\
\hline Empresa 7 & Entrevistado 7 & seguros & $5,800,000$ & 6,300 \\
\hline Empresa 8 & Entrevistado 8 & tecnologia & $39,250,000$ & 60,600 \\
\hline
\end{tabular}

O roteiro utilizado na entrevista está reproduzido a seguir:

\section{Família 1 - solidão e tomada de decisão}

Você já sentiu solidão no poder? Que tipo de solidão: física, psíquica? Você já sentiu solidão na tomada de decisão? Como você descreveria esta solidão: as pessoas do grupo não pensavam iguais a você? Você acredita que todas as decisões podem/devem ser discutidas e tomadas em grupo? Você acredita que a tomada de decisão em grupo dificulta a alocação de responsabilidades? Você acredita que a solidão no poder é própria somente de organizações cujas decisões são muito centralizadas? Estresse é uma condição de tensão que afeta as emoções. Você acredita que um dos causadores dessa tensão poderia ser o fato do sentimento de solidão estar presente nas pessoas que detêm o poder ou será que é a tensão que causa esse sentimento de solidão? Até que ponto o modelo de gestão participativa altera o sentimento de solidão no poder?

\section{Família 2 - solidão: liderança organizacional}

Será que em todos os cargos de liderança a solidão no poder é inerente? A solidão de um líder é importante e necessária? Você acredita que a solidão seja um fator de desmotivação? Você acredita que o clima da organização e o comportamento humano possam ser, de alguma forma, responsáveis pelo sentimento de solidão? Para alguns, a inspiração é própria, ou somente acontece em momentos solitários; ou seja, existe um lado construtivo na solidão? Você acha que é importante o isolamento para tomada de decisão?

Para reforçar e complementar a metodologia, essas duas famílias de assunto se subdividiram em categorias identificadas na Análise de Conteúdo, pela freqüência com que elas foram identificadas no discurso dos entrevistados e definidas na Tabela 3. Segundo Bardin (1977), a Análise de Conteúdo é empregada para avaliação da comunicação e destaca as interpretações de forma clara e siste- 
matizada das mensagens (quantitativas ou não) que permitam a inferência de conhecimentos relativos às condições de produção/recepção (variáveis inferidas) dessas mensagens. Nas entrevistas conduzidas, apesar do roteiro estruturado, permitimos total flexibilidade do discurso do entrevistado, justificando assim a utilização dessa técnica. Afinal, a Análise de Conteúdo é considerada uma técnica para o tratamento de dados que visa identificar o que está sendo dito a respeito de determinado tema (VERGARA, 2005); neste caso, Solidão no Poder das Organizações.

Para tanto, iremos analisar a freqüência com que as categorias foram abordadas e as respostas dadas às perguntas apresentadas acima. A freqüência das famílias de assunto foi analisada pelas Variáveis de Nível 1, conforme apresentado na Tabela 3. As abordagens das categorias e a relação com a solidão, conforme mostradas no roteiro das perguntas das entrevistas, foram seccionadas como mostrado na Tabela 3 e analisadas pelas Variáveis de Nível 2:

Tabela 3 - Famílias de Assunto e suas Abordagens

\begin{tabular}{|c|c|c|c|}
\hline $\begin{array}{l}\text { Famílias de } \\
\text { Assunto }\end{array}$ & $\begin{array}{l}\text { Variável Nível } 1 \\
\text { Família }\end{array}$ & Relação com a Solidão & $\begin{array}{l}\text { Variável Nível } 2 \\
\text { Categorias }\end{array}$ \\
\hline \multirow[t]{3}{*}{ Tomada de Decisão } & \multirow{3}{*}{ TD } & $\begin{array}{l}\text { Quando se incentiva a decisão em grupo, com a } \\
\text { discussão dos assuntos a decidir e distribui-se a } \\
\text { responsabilidade da decisão }\end{array}$ & TD Incentivada \\
\hline & & Quando não se delega responsabilidades & TD Não Incentivada \\
\hline & & Quando a decisão é do grupo & TD Grupo \\
\hline Liderança & $\mathrm{LI}$ & $\begin{array}{l}\text { Quando a percepção de que a solidão é um sentimento } \\
\text { necessário no cargo de liderança para trazer o } \\
\text { sentimento de criatividade e inovação na decisão }\end{array}$ & LI Positiva \\
\hline
\end{tabular}

Resrultardos

Anålise das $\mathbb{E}_{\text {mintrevistas }}$

A questão da solidão do poder foi analisada segundo as grandes famílias que permeiam a gestão organizacional, conforme o roteiro da entrevista apresentado na Metodologia.

\section{Solidão e Tomada de Decisão}

De acordo com as entrevistas, qualquer decisão que seja de fundamental importância para o futuro da empresa, raramente, é tomada em grupo. Os órgãos colegiados e as pessoas tecnicamente competentes são ouvidas e suas opiniões consideradas, mas na hora de "bater o martelo", a decisão fica por conta do primeiro executivo. Um dos executivos entrevistados nos deu o exemplo de uma decisão que teve que tomar sobre o fechamento de uma das fábricas de sua empresa. Segundo o Entrevistado 6, foi criado um grupo de trabalho para estabelecer a relação custo-benefício do fechamento, dando apoio à tomada de decisão. o grupo sugeriu o momento de fechamento, o auxílio financeiro que deveria ser pago aos funcionários a serem demitidos e quanto a decisão custaria para a empresa. No entanto, quem tomou a decisão final foi ele próprio.

Esse processo decisório, no qual se explicita claramente os limites da participação da autoridade e vincula a solidão no poder com a responsabilidade do cargo e da função, foi apresentado pela maioria dos entrevistados quando solici- 
tados para descrever o seu cotidiano gerencial. Percebe-se aqui, segundo Schlanger (1990), a presença do "pensador de fundo" e do "corredor de fundo". O primeiro aborda o pensar pela profundidade e não pela extensão; a solidão é um elemento inerente ao trabalho criador. O segundo tem uma postura existencial que reflete e amplifica a atividade do pensador de fundo, com obstinação, perseverança e repetição rítmica. Os trechos de entrevistas transcritos a seguir ilustram a questão:

A empresa não é uma democracia, eu e nem os componentes da minha equipe foram eleitos. A estrutura da empresa se assemelha muito ao de uma ditadura, só que nós temperamos essa ditadura com a participação. Então para que a sua decisão seja a melhor possível, você deve tratar isso com o maior número de pessoas possível. Agora, esperar que haja decisão de consenso é muito difícil. O grupo vai lhe dar subsídios, mas não irá, nem deve tomar a decisão por você. (Entrevistado 8)

Quando mais aumentam as decisões em grupo, mais decisões você vai ter que tomar sozinho, porque quando você traça uma decisão estratégica e todos cumprem aquilo, você não tem que tomar uma segunda decisão. Quando você tem um time participando da decisão, a cada passo surgem novas divergências, então você de novo é chamado a decidir. (Entrevistado 3)

A divisão de poderes não deveria gerar espaços para falta de comando. No entanto, numa cultura laissez faire, as pessoas utilizam a divisão de poderes para se isentar de assumir responsabilidades. É muito fácil transferir responsabilidades para os outros, mascarando a falta de coragem por detrás da cultura da participação. É o comportamento da "folga social", cuja tendência das pessoas é se esforçarem menos ao trabalhar em grupo em comparação a trabalhar sozinhas (LIDEN et al, 2003; 2004; COMER, 2000). O trecho da entrevista ao Entrevistado 7 ilustra a questão: "A gestão participativa não diminui a solidão no poder, mas atenua a responsabilidade de seu exercício". De acordo com as entrevistas, aceitar a solidão no poder é aceitar a individualidade e rejeitar o individualismo, conforme ilustra o trecho a seguir:

Quando a divisão de poderes é extrema, nós estamos à beira da anarquia; falta comando e as pessoas procuram se isentar de assumir responsabilidades. Hoje em dia, falta coragem às pessoas para assumir responsabilidades. É fácil transferir para os outros. Eu assumo responsabilidade nas decisões mais difíceis. Eu tenho que conviver com o estresse, com a pressão, com todo o tipo de ansiedade, mas acima de qualquer coisa, quem comanda, quem dirige tem que ter autoridade. (Entrevistado 1)

Há alguns tipos de decisões que precisam ser tomadas de maneira isolada. Com a disseminação da prática da gestão participativa, esse tipo de atitude, às vezes, é recriminada como centralizadora e como meio para se exercer o autoritarismo. Embora saibamos que a decisão seja isolada, o isolamento na formação da decisão é pernicioso, e o autoritarismo implica decisão sem participação na formação da opinião. A maioria dos entrevistados enfatizou que a autoridade é necessária, mas é preciso que se respeite a individualidade e se afaste o individualismo no processo participativo de formação de opinião. Inclusive, a busca por consenso é sinal de falta de liderança. Há situações em que não se pode ter consenso. Percebe-se, então, o fenômeno do pensamento grupal que engloba situações em que pressões para a conformidade impedem que o grupo avalie criticamente propostas incomuns, minoritárias ou impopulares, gerando sintomas como deteriorização da eficiência mental do indivíduo e busca de uma ilusão de unanimidade e moralidade. Então, ao invés de "perder tempo" tentando alcançar um consenso, a pessoa arrisca uma decisão isolada. É nesse momento que se instala a solidão. A pessoa está sozinha sem ter mais com quem discutir, pois já ouviu a opinião de todos. 
A decisão em grupo é muito útil, pois você minimiza os seus erros. Mas não são todas as decisões que se consegue tomar em grupo. Tem algumas decisões que você tem que tomar. Consenso é burrice ou falta de liderança. Tem hora em que você não tem consenso. Então, ao invés de perder tempo tentando alcançar um consenso, você arrisca uma decisão isolada. E aí onde chega a decisão, chega junto a solidão. Você está sozinho sem ter com quem discutir mais, pois já discutiu com todo mundo. Há momentos em que você tem que decidir sozinho. Não somente em questões estratégicas; das coisas mais bobas a decisões maiores. As circunstâncias o levam a decidir sozinho. A tendência das pessoas é entender isso como autoritarismo. Enquanto não atingi-las diretamente, elas fingem que não vêem, mas quando são atingidas, elas se revoltam brutalmente. (Entrevistado 3)

Esse tipo de decisão individual é, muitas vezes, confundido com autoritarismo. Uma das maneiras apontada pelos entrevistados para contornar tal situação foi ter a preocupação em mostrar que as decisões são do grupo. Quanto mais se conseguir passar para o time que a decisão não foi tomada de maneira isolada, melhor. Os trechos dos depoimentos reproduzidos, a seguir, esclarecem esses pontos:

Para motivar as pessoas a participarem da tomada de decisão, é preciso fazer com que elas realmente sintam que participaram... Aqui na empresa eu nunca faço nada se não houver um campeão atrás de mim... Sei que a pessoa quando quer, faz com que as coisas aconteçam. (Entrevistado 4)

Por outro lado, alguns entrevistados foram de opinião de que o grupo espera que haja alguém que diga: "Ouvidas todas as opiniões, agora a decisão é minha", declara o Entrevistado 8. O dirigente de empresa que apela demais para decisões coletivas em assuntos importantes para a estratégia da empresa, toma uma posição que pode ser facilmente confundida e interpretada como falta de coragem e que, para o caso de insucesso, a responsabilidade passaria a não ser sua, mas de um grupo. É o fenômeno da "folga social", visto novamente. Um parágrafo da entrevista mostrada abaixo ilustra o tema:

Nas horas difíceis, esta abertura e participação não são bem verdades porque alguém tem que decidir. E uma decisão afeta tantos interesses que, caso seja participativa, corre o grave risco de não conseguir ter sucesso em uma decisão. Neste momento, tem-se o sentimento de solidão. (Entrevistado 5)

Por fim, é interessante ressaltar a posição dos entrevistados no que diz respeito à chamada "liturgia do cargo". Na opinião dos dirigentes, o líder tem que saber dar espaço às pessoas, mas, ao mesmo tempo, exercer sua autoridade. Segundo o Entrevistado 7, a autoridade é necessária, respeitando a individualidade e afastando o individualismo no processo participativo de formação de opinião.

\section{Solidão e Liderança Organizacional}

Quando se fala em liderança, relaciona-se este tema à tomada de decisão. Portanto, de acordo com a opinião dos entrevistados, a solidão no poder é inerente a quem toma decisões, em função da responsabilidade de dirigir uma organização. Todos os entrevistados afirmaram sentir solidão. As entrevistas apontaram a importância física do isolamento, às vezes necessário para que uma decisão seja tomada. As entrevistas enfatizaram, também, a pressão emocional e incerteza, presentes em todas as decisões.

Quem dirige tem que ter seu ambiente de estar só. É importante, porque é o telefone, é uma conversa privada, é o seu lugar de reflexão, onde você está à vontade para caminhar, falar, sentar para tomar sua decisão. Pode ser psíquica, também, sob o ponto de vista da pressão. É natural que na hora das grandes decisões, as estratégicas, as complicadas, você tenha uma pressão emocional, uma pressão psíquica enorme, porque no momento de tomar a decisão uns levarão vantagens e outros deixarão de ter. Eu vejo que os dois tipos de solidão existem. (Entrevistado 1) 
A maioria dos empresários entrevistados mostrou uma habilidade em tolerar altos níveis de solidão no processo decisório. Inclusive, consideram a solidão necessária. A necessidade de possuírem essa habilidade cresce na medida em que as responsabilidades aumentam. A solidão pode ser considerada, também, como uma das características mais importantes nas atitudes e comportamentos de um líder, já que as exigências se tornam mais fortes e divergentes. Percebe-se, nesses casos, que as lideranças devem desempenhar o papel solitário de "advogado do diabo" para que a tomada de decisão não sofra com os sintomas apontados do pensamento grupal.

Tem decisões que você tem que estar sozinho. Você tem que ter uma capacidade absurda de conviver com a solidão. Eu não consigo tomar decisões com muito barulho por perto, mas, no ambiente de trabalho, eu consigo me abstrair, na minha mesa... A solidão é necessária. O fato de você ter um ambiente informal onde as pessoas têm acesso a hora que querem não te dá a liberdade de dizer "agora não"... Eu não fico ansioso sozinho. Você não precisa ser necessariamente um solitário. Eu tenho capacidade de viver só, com prazer, com equilíbrio, mas também eu gosto do oposto. (Entrevistado 3)

Uma alternativa para a difícil tarefa de tentar racionalizar o processo decisório dos executivos é aumentar a racionalidade dos sistemas e processos organizacionais. Os sistemas de suporte às decisões e o planejamento estratégico são fontes de racionalização organizacional.

As empresas têm usado sistemas racionais para a coleta de informação, planejamento estratégico, orçamento, planejamento de Recursos Humanos e análise ambiental há muito tempo. Esses sistemas são úteis e necessários como um complemento à aparente inabilidade das lideranças em serem sistemáticas e racionais em sua maneira de pensar; mas nem sempre libertam os executivos de atacar tarefas ambíguas e mal definidas que só a mente humana é capaz de formular.

Nesse processo, às vezes, muitos dos entrevistados buscam arrumar tempo para pensamentos profundos quando estão sozinhos ou quando conseguem exercitar um distanciamento e isolamento dos problemas. A maioria deles, constantemente, mantém a sua habilidade de reflexão, a fim de melhor analisar suas experiências passadas e atuais. Eles lêem livros fora de seus campos de atuação, se envolvem em discussões políticas e econômicas, assistem aulas e seminários sobre gestão, participam de atividades culturais, sociais e esportivas. Dessa maneira, os dirigentes estão desenvolvendo seus recursos mentais críticos que poderão ser aplicados a problemas que surgem em seus trabalhos. Muitos empresários têm consciência que suas melhores idéias surgem em algum lugar que não o escritório: numa longa viagem de avião, no caminho de casa para o trabalho, na hora relaxante do banho; quase sempre em momentos solitários, considerados pela maioria das pessoas como perdas de tempo.

Observamos no cotidiano gerencial a criatividade desabrochar com muito mais facilidade fora do ambiente de trabalho. Quanto mais alto o posto ocupado pelo executivo, mais amplos devem ser seus interesses de vida, já que, provavelmente, ele chegou ao limite do conhecimento e do exercício de atributos profissionais, como capacidade de gerenciamento, controle e planejamento. Portanto, é quando a intuição e a capacidade de isolamento fazem uma enorme diferença e o executivo pode vivenciar uma solidão criativa. O trecho da entrevista, abaixo, ilustra esta questão:

Eu acredito que o ócio é muito criativo. Todas as grandes inovações eu procurei tirar no meio do ócio e da solidão. É preciso certo distanciamento para saber o que fazer, saber quais decisões tomar e a quem elas vão afetar, se as mudanças vão machucar alguém. (Entrevistado 4)

Nesse processo organizacional, a cultura, mais do que a estratégia e a estrutura, tem um papel fundamental no comportamento dos empresários diante da solidão do poder. No que diz respeito aos atributos visíveis do ambiente físico das organizações, podemos analisar essa questão sob duas perspectivas: determinante do comportamento e aspecto do comportamento. 
As entrevistas confirmam os estudos feitos em grupos socialmente isolados, apresentados no referencial teórico, na medida em que ilustram o papel do ambiente como determinante do comportamento e, também, como um veículo de comportamento pessoal. A seleção prévia da estrutura ambiental estabelece as fronteiras dentro das quais a interação social pode ocorrer. O layout dos móveis numa sala ou escritório e a iluminação irão, de certa maneira, pré-estruturar as trocas interpessoais. O design do ambiente, especialmente a proximidade, parece estar intimamente relacionado com a interação, integração, amizade e abertura mútua (TOMEI, 2008).

No aspecto do comportamento, quem dirige tem que ter seu ambiente para estar só. Na hora de determinadas decisões, o executivo gosta de estar sozinho para refletir e traçar estratégia a ser seguida. Por mais que a pessoa consiga se isolar mentalmente, apesar de não estar isolada fisicamente, as mais variadas preocupações no ambiente de trabalho, às vezes, prejudicam o processo criativo na tomada de decisões. Sendo assim, tornam-se necessários períodos de isolamento temporário para que a criatividade aflore.

\begin{abstract}
Às vezes eu tenho a necessidade de ficar sozinho. Eu tenho o prazer de ficar sozinho. Às vezes eu libero a agenda numa manhã de compromissos, deixo de ser escravo do cargo e fico analisando as estratégias da empresa. Quando se está em grupo, sua importância está diluída; eu consigo, sem estar isolado fisicamente, ficar isolado mentalmente. Mas não é tão eficaz. Um ponto gerencial importante é essa necessidade de isolamento. Acho que a falta de formação leva as pessoas a procurarem outras formas de criatividade como meditação etc. Uma formação direcionada à cultura aumenta o poder criativo. Eu, por exemplo, detesto ler livros de Administração. As pessoas que têm atividade racional muito intensa devem compensar isso com concertos de música clássica, por exemplo. Devem trabalhar a criatividade e a inovação de outra forma. (Entrevistado 6)
\end{abstract}

Para que a estrutura ambiental alavanque uma cultura na qual a solidão tenha espaço, é preciso internalizar a crença de que a separação dos outros oferece "um retorno a si mesmo" e de que a sociabilidade aleatória não só não constitui antídoto à solidão, mas, em muitos casos, pode até exacerbá-la, conforme vimos no referencial teórico. Esse é o tipo de solidão em que a pessoa não está apenas sozinha, mas também é capaz de usar sua solidão para reconhecer com clareza tanto a sua separação de todo o resto, como sua conexão fundamental com todo o resto. A pessoa é, então, capaz de reconhecer seu eu mais profundo e, assim, começar a ser esse ser verdadeiro. Nesse contexto, a totalidade do indivíduo é estabelecida por meio da integração da consciência e do inconsciente coletivo.

Numa organização que pretende desenvolver uma cultura de aprendizagem, é preciso incentivar a aprendizagem individual e o gerenciamento da sua solidão. É preciso ajudá-los a compreender e vivenciar a filosofia de Nietzsche (1905). Seguindo os passos da tradição grega, o filósofo afirma que a solidão é uma condição da vida, e que é esta luta contra o inevitável que causa dor, sofrimento, angústia e ansiedade naqueles que estão sozinhos. Para o autor, a solidão é, na verdade, um estado de lucidez, de compreensão pessoal e criação, no qual se pode criar valores, coisas e possibilidades.

Em organizações nas quais as culturas facilitam os indivíduos a lidarem com as questões básicas da vida, se tem maior espaço para o crescimento e a maturidade individual e organizacional. Para isso, é preciso que se viabilize uma quebra de paradigma em que a vivência da solidão é vista de forma negativa. O medo da solidão está relacionado ao medo de viver, de errar e de aprender.

A liderança, a tomada de decisão é uma prática. Você tem que adquirir confiança em si mesmo... Você se baseia no que ouve, vê e lê. Você tem que concatenar isto, tem que ter um poder de síntese e tirar sua conclusão para tomar a decisão. (Entrevistado 2)

Aceitar a solidão é uma alternativa para manifestar as diferenças e introduzir a criatividade e a inovação nas organizações. Se os indivíduos e as organiza- 
ções não usarem o espaço do vazio solitário para se descobrirem e entrarem em contato com a sua própria identidade, eles serão sempre mais um na multidão e perderão qualquer tipo de vantagem competitiva. Dessa forma, num ambiente organizacional, a "distância digna" deve ser mantida, dosando informalidade com respeito. A informalidade deve ser estimulada, desde que as pessoas tenham maturidade para isso. É preciso que o líder reserve o direito de dizer "agora não", mesmo mantendo suas portas abertas.

\section{Annallise dle Connterido}

A análise de conteúdo reforça os resultados das interpretações das entrevistas, conforme mostrado nos gráficos abaixo. Essa análise será feita de forma breve, somente para ilustrar toda a análise das entrevistas, apresentada no item anterior.

As famílias de Tomada de Decisão (TD) e Liderança (LI) foram igualmente abordadas, mostrando evidências e dando subsídios para a interpretação dos dados de forma clara e coerente. As famílias de assunto tiveram citações em torno de 43 a 46 vezes por todos os entrevistados, conforme Gráfico 1.

\section{Gráfico 1 - Famílias}

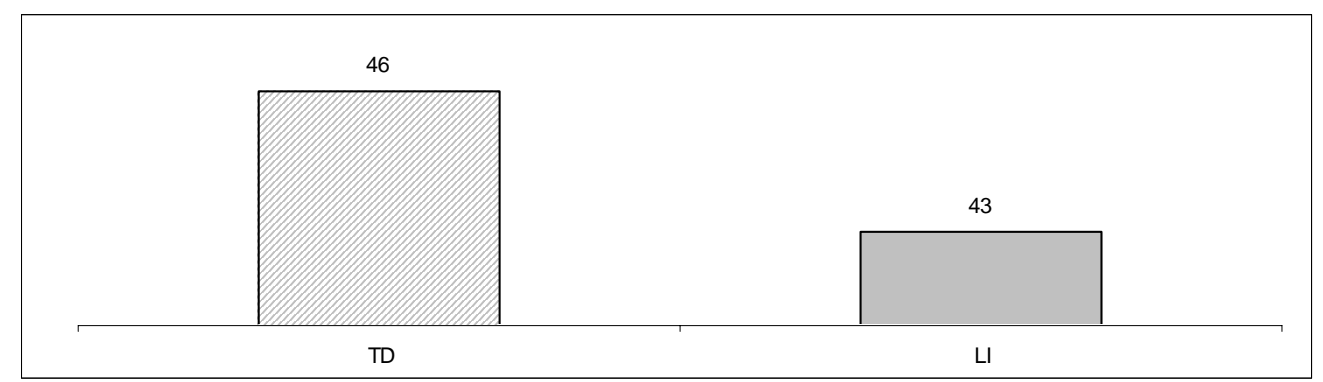

Dentro dessas famílias, pode-se constatar, pelo Gráfico 2, que quando se fala em Tomada de Decisão (TD), a maioria dos entrevistados adotam uma tomada de decisão não incentivada (TD-Não Incentivada - 15), ou seja, a decisão não é tomada por um consenso. Na hora da decisão final, uma só pessoa decide, conforme constatamos nos scores referentes à tomada de decisão individual (TD-Decisão Individual - 18) em comparação com a tomada de decisão em grupo (TD-Decisão Grupo - 6). Nesse tema, foi mostrado que por mais que o discurso organizacional incentive a decisão participativa, a tomada de decisão é de uma só pessoa, que assume a responsabilidade das conseqüências da sua escolha. Esse líder, para decidir, precisa controlar o medo implícito da solidão do poder para exercer sua autoridade e acaba vendo a solidão como um momento de criatividade, inovação, ou seja, uma solidão positiva (LI Positiva - 16 e; LI Negativa - 4). Muitos não encaram a decisão solitária como comportamento monopolista e/ou sofredor, e não demonstraram o medo de assumir a responsabilidade de poder errar.

A seguir, no Gráfico 2, apresenta-se a freqüência com que as categorias foram abordadas. 


\section{Gráfico 2 - Abordagem das Categorias}

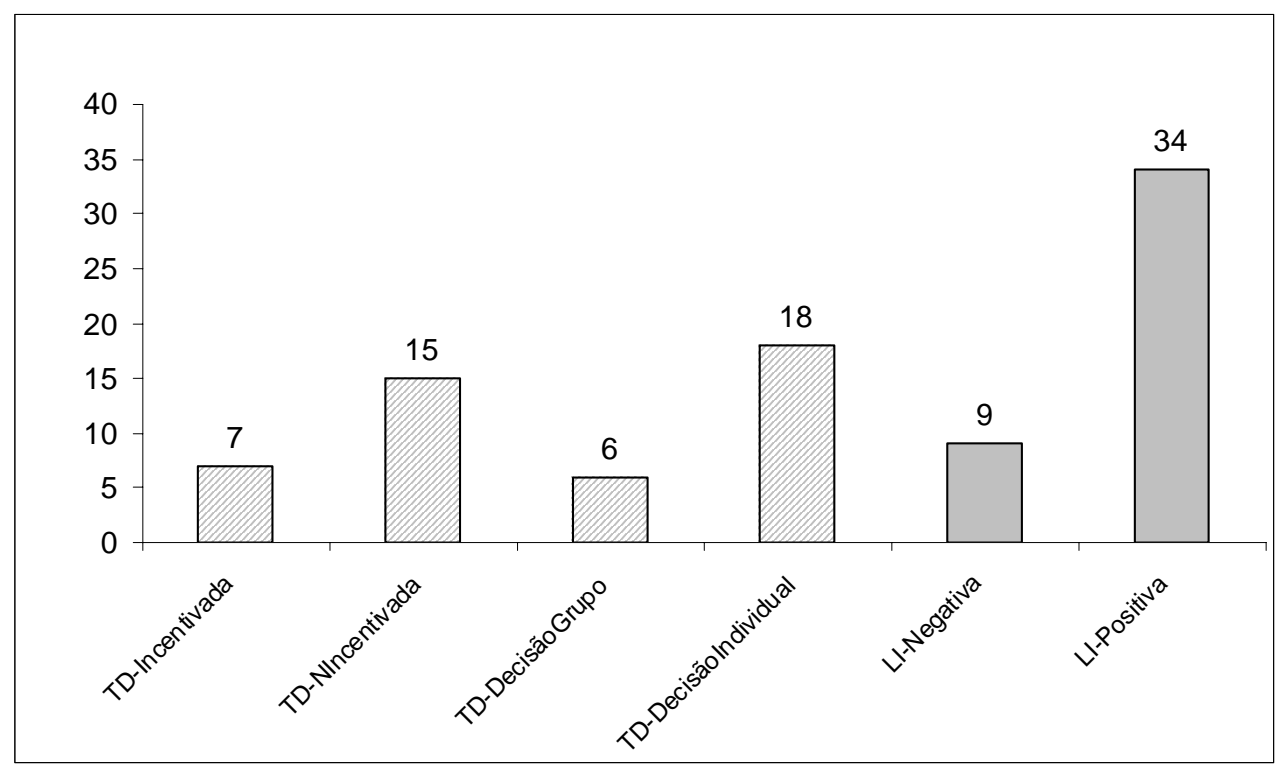

Comclursão

Esta pesquisa exploratória nos ajudou a refletir sobre o papel que a solidão no poder exerce no cotidiano gerencial. Ela não nos permite afirmações conclusivas sobre o tema, mas levanta evidências do que se vivencia nas organizações em relação aos dois tipos de solidão: a solidão no poder (loneliness) e a solidão do poder (solitude) em graus diferentes de intensidade, segundo a contingência. $\mathrm{Na}$ maioria das organizações analisadas, casos extremos de solidão no poder não ocorre, ou sequer é considerado. É o caso em que a pessoa não tem apoio dos demais dentro da organização ou o seu poder traz uma sensação ruim. Vivenciase, no âmbito de liderança, a solidão do poder. Essa solidão é necessária, pois ativa e reforça a condição de responsabilidade e a necessidade de reflexão daquele que detém o poder. Nesse sentido, a solidão pode funcionar como alternativa propulsora de maior criatividade e inovação na definição de estratégias que enriqueçam o processo decisório.

Observamos nas entrevistas que existe uma consciência explícita dos empresários referente à necessidade de aprender a ficar sozinho, que é associada à dificuldade de assumir riscos. O sentimento de solidão pode ser considerado, nesse contexto, como mais uma barreira na tomada de decisão em grupo, reforçando o discurso do teamwork e do empowerment como modismos empresariais difíceis de serem operacionalizados na prática.

Cada vez mais se defende, nas organizações e na sociedade, uma busca por modelos participativos, que nem sempre são viáveis, principalmente em contextos de organizações globais. Nelas, os sistemas de dominação, exploração e controle muitas vezes induzem a situações, nas quais observamos a solidão dos indivíduos sob o poder das organizações.

Apesar do aprofundamento do discurso humanista ser fundamental nos estudos organizacionais, não o priorizamos neste artigo e fica como uma sugestão para trabalhos futuros. Dentro da perspectiva da busca da eficiência organizacional proposta neste artigo, concluímos que aprender a ficar só e usufruir das vantagens da solidão criativa e inovadora são consideradas competências essenciais para a vantagem competitiva. O crescimento da tecnologia e, especialmente, no 
que tange à condição do aprendizado solitário e do auto-aprendizado demandarão abordagens cada vez mais realistas da questão.

É necessário que pesquisas sobre a solidão no poder aprofundem este tema na discussão acadêmica e empresarial. O aprofundamento deve ir na direção de tentar relacionar solidão com a liderança, a tomada de decisão, a criatividade e a inovação nas organizações modernas.

\section{Referềncials}

ALTMAN, I.; HAYTHORN, W. W. Interpersonal exchange in isolation. Sociometry, v.28, n.4, p.411-426, 1965.

The effects of social isolation and group composition on performance. Human Relations, v.20, n.4, p.313-340, 1967.

ANGERAMI, V. Suicídio. Uma alternativa à vida. Uma visão clínica existencial. São Paulo: Traço Editora, 1986.

BARDIN, L. Análise de conteúdo. Paris: Presses Universaire de France, 1977.

BARON, R. S. So right it's wrong: groupthink and the ubiquitous nature of polarized group decision making. Advances in Experimental Social Psychology, v.37, p.219-253, 2005.

BOYD, D. P.; GUMPERT, D. E. Coping with entrepreneurial stress. Leadership and Organization Development J ournal, v.13, n.2, p. 27-32, 1992.

CARTER, M. Abiding loneliness: an existential perspective. Illinois: Park Ridge Center, 2000.

$\mathrm{CHOI}, \mathrm{J} . \mathrm{N} . ; \mathrm{KIM}, \mathrm{M}$. U. The organizational application of groupthink and its limits in organization. Journal of Applied Psychology, v.84, n.2, p297-306, 1999.

COMER, D. R. A model of social loafing in a co-operative classroom task. Educational Psychology, v. 20, n.4, p.389-392, 2000.

DELEUZE, G. Spinoza: philosophie pratique. Paris: Ed. de Minuit, 1981.

ENRIQUEZ, E. Talk show acadêmico - gestão participativa. CELTEC Multimídia. 1995 CD-ROM. Entrevista concedida à Patricia Tomei.

ESSER, J. K. Testing the groupthinking model: effects of promotional leadership and conformity predisposition. Social Behavior and Personality, v.29, n.1, p.31-41, 2001.

EVANS, F. B. Harry stack sullivan: the interpersonal theory and psychotherapy. Londres: Ed. Routledge, 1996.

FOUCAULT, M. Histoire de la folie a l'age classique: suivi de mon corps, ce papier, ce feu et la folie, l'absence d'oeuvre. Paris: Gallimard, 1972.

GLADWELL, M. Blink: the power of thinking without thinking. Boston: Little, Brown and Company, 2005.

GUSTAFSSON, L. A classe média sai do paraíso. In: Jornal O Globo. Rio de Janeiro. 30 de outubro, 1994.

JACKSON, J. M.; HARKINS, S. G. Equity in effort: an explanation of the social loafing effect. Journal of Personality and Social Psychology, v.49, n.5, p.1199-1206, 1985.

; WILLIAMS, K. D. Social loafing on difficult tasks. Journal of

Personality and Social Psychology, v.49, n.4, 937-942, 1985.

JANIS, I. L. Victims of groupthink. Boston: Houghton Mifflin, 1972. 
KANT, I [1787]. Crítica da razão pura. Trad. de Manuela P. dos Santos e Alexandre F. Morujão. Lisboa: Calouste Gulbenkian, 1997.

KARAU, S. J.; WILLIAMS, K. D. Social loafing: a meta-analytic review and theoretical integration. Journal of Personality and Social Psychology, v.65, n.4, p.681-706, 1993.

KATZ, C. S. O coração distante: ensaio sobre a solidão positiva. Rio de Janeiro: Editora Revan, 1996.

KAUFMANN, A.; ALVES, A. C. A solidão no poder. In: Revista Vida Executiva, v.36, maio 2007.

KLEIN, M. O sentimento de solidão: nosso mundo adulto e outros ensaios. Rio de Janeiro: Imago, 1971.

KRAVITZ, D. A.; MARTIN, B. Ringelmann rediscovered: the original article. J ournal of Personality and Social Psychology, v.50, n.5, p.61-84, 1986.

LATANE, B.; WILLIAMS, K.; HARKINS, S. Many hands make light the work: the causes and consequences of social loafing. Journal of Personality and Social Psychology, v.37, n.6, p.822-832, 1979.

LIDEN, R. C.; WAYNE, S. J.; JAWORSKI, R. A.; BENNETT, N. Social loafing: a field investigation. Journal of Management, v.30, n.2, p.285-304, 2004.

LUTHANS, F.; HADGETTS, R. M.; ROSENKRANTZ, A. Real managers. Cambridge: Ballinger, 1988.

MARANO, H. E. Solitude vs loneliness. Psychology Today Magazine, jul/aug 2003. Disponível em: <http://www.psychologytoday.com/articles/index>. Acesso em: 28 nov. 2004.

MAY, R. O homem à procura de si mesmo. Petrópolis: Ed. Vozes, 1987.

MCCAULEY, C. The nature of social influence in groupthink: compliance and internalization. Journal of Personality and Social Psychology, v.57, n.2, p.250-260, 1989.

MCPHERSON, M.; SMITH-LOVIN, L.; BRASHEARS, M. E. Social isolation in America: changes in core discussion networks over two decades. American Sociological Review, v.71, n.3, p.353-375, 2006.

MINTZBERG, H. The nature of managerial work. Nova Iorque: Pearson Education, 1973.

NIETZSCHE, F. W. The philosophy of Nietzsche. Nova Iorque: The Modern Library 1905.

PAZ, O. O labirinto da solidão e post scriptum. Rio de J aneiro: Editora Paz e Terra, 1984.

ROSSI, R. Teresa de Ávila. Biografia de uma escritora. Rio de Janeiro: José Olympio, 1988.

ROTHWELL, J. D. In the company of others: an introduction to communication. Califórnia: Mayfield Publishing Company, 2000.

RUSSEL, B. Authority and the individual. Londres: George Allen \& Unwin, 1949. SANTO AGOSTINHO. Confissões. In: Os pensadores. São Paulo: Nova Cultural, 1984.

SARTRE, J. P. O existencialismo é um humanismo. Lisboa: Editorial Presença, 1978.

SCHLANGER, J. Solitude du penser de fond. Paris: Ed. Criterion, 1990. 
TANNER, I. J. Solidão: o medo do amor. Rio de Janeiro: Ed. Record, 1979.

TOMEI, P. A. "TALK SHOW ACADÊMICO - GESTÃO PARTICIPATIVA" entrevista

Eugéne Enriquez, CD-ROM, CELTEC Multimídia, 1995.

. Delegação de autoridade. PDG/ BNDES, 2004.

. Cultura e mudança organizacional. Rio de Janeiro: Editora PUC-Rio,

2008.

; CHERMAN, A. Códigos de ética corporativa e a tomada de decisão ética: instrumentos de gestão e orientação de valores organizacionais. Revista de Administração Contemporânea - RAC, v.9, n.3, p.99-120, 2005.

VERGARA, S. C. Métodos de pesquisa em administração. São Paulo: Atlas, 2005.

WEISS, R. S. Loneliness: The experience of emotional and social isolation.

Cambridge: MIT Press, 1974. 